\title{
Epigallocatechin-3-gallate inhibits the PDGF-induced VEGF expression in human vascular smooth muscle cells via blocking PDGF receptor and Erk-1/2
}

\author{
JUNG S. PARK, MI H. KIM, HEE J. CHANG, KI M. KIM, SEOK M. KIM, \\ BOO A. SHIN, BONG W. AHN and YOUNG D. JUNG \\ Chonnam University Research Institute of Medical Sciences, \\ Chonnam National University Medical School, Kwangju 501-190, Korea
}

Received May 5, 2006; Accepted July 3, 2006

\begin{abstract}
Platelet-derived growth factor (PDGF) has been known to induce vascular endothelial growth factor (VEGF) expression in human vascular smooth muscle cells (hVSMCs). We previously reported that Erk-1/2 and AP-1 pathways are crucial in the PDGF-induced VEGF expression in hVSMCs . In this study, we investigated the effect of epigallocatechin-3gallate (EGCG), the major green tea catechin, on the PDGFinduced VEGF expression in hVSMCs and the underlying mechanisms. EGCG were found to inhibit dose-dependently the VEGF expression and activation of PDGF receptor, Erk-1/2 and AP-1 induced by PDGF. In addition, cell free studies demonstrated that EGCG could directly inhibit the Erk-1/2 activity. Conditioned media from the hVSMCs treated with PDGF could remarkably stimulate the in vitro growth of human umbilical vein endothelial cells (HUVECs) but the media from the EGCG-pretreated hVSMCs lost its stimulatory activity for HUVEC proliferation. These results suggest that EGCG may exert the anti-angiogenic effect by inhibiting the PDGF-induced VEGF expression at multiple signaling levels.
\end{abstract}

\section{Introduction}

Epidemiological studies have suggested that ingestion of green tea may decrease cancer risk $(1,2)$. In addition, many pre-clinical studies have provided convincing evidence that some substances of green tea may afford protection against cancer $(3,4)$. The anti-carcinogenic effects of green tea have been attributed to the biological activity of its polyphenol components. Green tea extract contains catechins such as (-)-epigallocatechin gallate (EGCG), (-)-epigallo-catechin (EGC), (-)-epicatechin gallate (ECG), and (-)-epicatechin

Correspondence to: Dr Young D. Jung, Department of Biochemistry, Chonnam National University Medical School, 5 Hakdong, Kwangju 501-190, Korea

E-mail: ydjung@chonnam.ac.kr

Key words: epigallocatechin-3-gallate, PDGF, VEGF, vascular smooth muscle cells, Erk-1/2
(EC) (5). EGCG has been reported to prevent tumor invasion and angiogenesis that are essential processes for tumor growth and metastasis (6). Our previous results showed that treatment of mice with EGCG resulted in marked inhibition of vascularity and proliferation of human colon cancer xenografts in nude mice (3).

Endothelial cells (ECs) and vascular smooth muscle cells (VSMCs) are the major cellular components of small tumor vessels. Interactions between these cells play significant roles in the homeostasis of the structure and function of the blood vessel (7). Angiogenesis, the growth of novel capillaries from pre-existing vessels, is an essential step in tumor growth and metastasis (8). The formation of new blood vessels is mediated by angiogenic growth factors (9). The growth factors not only bind their receptors on ECs and stimulate the cell proliferation initiating new blood vessel formation but also bind receptors on accessory cells such as VSMCs that maintain vessel integrity (10). One of the most potent angiogenic factors is vascular endothelial growth factor (VEGF), which stimulates capillary formation and has specific mitogenic and chemotactic activity for vascular ECs (11). VEGF is produced by various cell types, including ECs, VSMCs, fibroblasts, epithelial cells, mesenchymal cells, and macrophage (11-13). A variety of cytokines and growth factors, including IL-1, IL-6, PDGF-BB, TGF, basic fibroblast growth factor, and hepatocyte growth factor have been shown to induce VEGF expression in malignant and non-malignant cell lines (11). In previous reports, we suggesed that ERK-1/2 and AP-1 signaling pathways are involved in the PDGF-induced VEGF expression in human VSMCs (hVSMCs) and that these paracrine signaling pathways induce endothelial cell proliferation (14).

In the present study, we have found that EGCG inhibits the PDGF-induced VEGF expression in hVSMCs and investigated the effects of EGCG on the signaling pathways which are suggested to be involved in the VEGF expression.

\section{Materials and methods}

Cell culture and reagents. hVSMCs were obtained from American Type Culture Collection (Rockville, MD) and cultured in Hanks modified Dulbecco's minimal essential medium (DMEM) supplemented with $10 \%$ fetal bovine serum (FBS) and $2 \mathrm{U} / \mathrm{ml}$ penicillin-streptomycin at $37^{\circ} \mathrm{C}$ in 
$5 \% \mathrm{CO}_{2}$. Human umbilical vein endothelial cells (HUVECs) were obtained from American Type Culture Collection and cultured in DMEM supplemented with $15 \%$ FBS and $5 \mathrm{ng} / \mathrm{ml}$ basic fibroblast growth factor (FGF). PDGF (PDGF-BB) was purchased from R\&D Systems, Inc. (McKinley Place, NE). EGCG, EC, ECG, and EGC were obtained from Sigma Chemical Co. (St. Louis, MO). The rabbit polyclonal antiphosphospecific p44/42 MAPK (Erk-1/2), anti-phosphospecific JNK, and anti-phosphospecific P38 MAPK antibodies were purchased from New England Biolabs, Inc. (Beverly, MA), and anti-PDGF-ßR and anti-phosphotyrosine antibodies were from Santa Cruz Biotechnology, Inc. (Santa Cruz, CA).

Northern blot analysis. Total RNA extraction and Northern blot hybridization were performed as previously described (14). The cDNA probe for VEGF was generated by PCR using sense (5'-TCCAGGAGTACCCTGATGAG-3') and antisense (5'-ATTCACATTTGTTGTGCTGT-3') primers (15). The glyceraldehyde-phosphate dehydrogenase (GAPDH) probe was purchased from American Type Culture Collection. Each cDNA probe was radiolabeled with $\left[\alpha-{ }^{32} \mathrm{P}\right]$ deoxyribonucleoside triphosphate by the random-priming technique using the Rediprime labeling system (Amersham Corp., Arlington, IL). The probed nylon membranes were exposed to radiographic films (Life Technologies, Inc., Grand Island, NY). To examine the effects of catechins on VEGF induction by PDGF, hVSMCs were pretreated with 0-50 $\mu \mathrm{M}$ catechin for $1 \mathrm{~h}$ prior to exposure to PDGF, and the level of VEGF mRNA was measured by Northern blot analysis.

ELISA for VEGF concentration. The concentration of VEGF in the culture supernatants was measured by ELISA using a commercially available kit (Immunoassay Kit Human VEGF; BioSource International, Camarillo, CA). Briefly, samples were incubated in microtiter plates precoated with a monoclonal antibody specific for VEGF. After incubation at room temperature for $2 \mathrm{~h}$ and washing, the substrate solution was added. Color development was stopped after $30 \mathrm{~min}$ at room temperature, and the color intensity was read at $450 \mathrm{~nm}$ within $30 \mathrm{~min}$.

Measurement of VEGF promoter activity. A 2951-bp fragment containing the 5' flanking region and transcriptional start site of the VEGF gene $(-2362-+589 \mathrm{bp})$ was prepared by PCR with genomic DNA of VEGF as a template. The specific primers contained KpnI and SmaI linker sites (16). This PCR product was cloned into the pGL3-Basic vector (Promega, Madison, WI) to make a VEGF promoter-luciferase reporter construct (pGL3-VEGF). hVSMCs $\left(5 \times 10^{5}\right)$ were seeded and grown to $60-70 \%$ confluence, and then pRLTK (an internal control plasmid containing the herpes simplex thymidine kinase promoter linked to the constitutively active Renilla luciferase reporter gene) and pGL3-VEGF were cotransfected into cells using FuGENE (Boehringer Mannheim, Indianapolis, IN) according to the manufacturer's protocol. pRLTK and pGL3 were cotransfected as a negative control. Cells were incubated in the transfection medium for $20 \mathrm{~h}$ and treated with PDGF for $8 \mathrm{~h}$. The effect of EGCG on VEGF promoter activity was determined by pretreating cells with EGCG for $1 \mathrm{~h}$ prior to addition of PDGF. Cells were harvested with passive lysis buffer (Dual-Luciferase Reporter Assay System; Promega), and the luciferase activity was determined using a single sample luminometer according to the manufacturer's protocol.

Immunoprecipitation. hVSMCs, after treatment with EGCG at the indicated concentration, were lysed in radioimmune precipitation buffer $(150 \mathrm{mM} \mathrm{NaCl}, 50 \mathrm{mM}$ Tris, $0.1 \%$ SDS, $1 \%$ Nonidet P-40, $0.6 \%$ sodium deoxycholate, $1 \mathrm{mM}$ iodoacetamide, $1 \mathrm{mM}$ phenylmethylsulfonyl fluoride, and 0.2 units of aprotinin). The proteins $(100 \mu \mathrm{g})$ in each sample were incubated with $1 / 10$ volume of Protein G-Sepharose beads (Amersham Corp.) for $1 \mathrm{~h}$ to eliminate non-specific binding. The protein samples were incubated with the $1: 100$ dilutions of anti-PDGF-ßR, anti-Erk-1/2, anti-JNK and antiP38 MAPK antibodies at $4^{\circ} \mathrm{C}$ overnight. Protein G-Sepharose ( $1 / 10$ volume) was then added and incubated for $1 \mathrm{~h}$ at $4^{\circ} \mathrm{C}$. The beads were washed four times with lysis buffer followed by two washing with kinase buffer (50 mM HEPES, pH 7.5, $10 \mathrm{mM} \mathrm{MgCl}_{2}, 2.5 \mathrm{mM}$ EGTA, $1 \mathrm{mM}$ dithiothreitol, $5 \mathrm{mM}$ ß-glycerophosphate, $0.1 \mathrm{mM}$ sodium orthovanadate, and $1 \mathrm{mM} \mathrm{NaF}$ ). Samples were boiled for $3 \mathrm{~min}$ before Western blot analyses. For in vitro kinase assays, the immunoprecipitated kinase bound to the beads was incubated in kinase buffer supplemented with $20 \mathrm{pM}$ ATP, and $1 \mu \mathrm{g}$ protein substrate. Reactions were stopped by the addition of equal volume of $2 X$ Laemmli buffer followed by SDS-PAGE. The specific kinase activities were measured by the nonradioactive kinase assay using the kits purchased form Cell Signaling Technologies (Danvers, MA).

Western blot analysis. Western blot analysis was performed as previously described (14). The primary antibody preparations used in this study were 1:1000 dilutions of rabbit polyclonal anti-phosphotyrosine and anti-phosphospecific ERK-1/2 antibodies. The secondary antibody was horseradish peroxidase-labeled anti-rabbit immunoglobulins from donkey (Amersham Corp.) used at a 1:3000 dilution. Protein bands were visualized using a commercially available chemiluminescence kit (Amersham Corp.). Total protein levels were assayed by washing the blotted membrane with stripping solution [(100 mM 2-mercaptoethanol, 2\% sodium dodecyl sulfate, and $62.5 \mathrm{mM}$ Tris- $\mathrm{HCl}(\mathrm{pH} 6.7)]$ for $30 \mathrm{~min}$ at $50^{\circ} \mathrm{C}$ and then reprobing the membrane with rabbit polyclonal antiPDGF-ßR and anti-p44/42 antibodies diluted at 1:1000.

Extraction of nuclear proteins. hVSMCs (80-90\% confluent) were incubated overnight in medium containing $1 \%$ FBS and treated with $0-10 \mathrm{ng} / \mathrm{ml}$ PDGF for $8 \mathrm{~h}$. The cells were then resuspended in $500 \mu 1$ cold buffer A [50 mM Tris ( $\mathrm{pH} 7.4)$, $150 \mathrm{mM} \mathrm{NaCl}, 0.2 \mathrm{mM}$ EDTA, 3\% (v/v) glycerol, and $1.5 \mathrm{mM}$ $\mathrm{MgCl}_{2}$ ]. After the cells were allowed to swell for $5 \mathrm{~min}$ on ice, they were lysed with $500 \mu 1$ buffer B [identical to buffer A except containing $0.05 \%$ Nonidet P-40 (Sigma)]. The homogenate was gently layered onto an equal volume cushion of buffer C [10 mM Tris (pH 7.4), 25\% (v/v) glycerol, and $1.5 \mathrm{mM} \mathrm{MgCl} 2]$ and centrifuged for $5 \mathrm{~min}$ at $200 \mathrm{x} \mathrm{g}$. The white nuclear pellet was resuspended in $75 \mu 1$ cold high-salt lysis buffer [20 mM HEPES (pH 7.9), $400 \mathrm{mM} \mathrm{NaCl}, 1 \mathrm{mM}$ 


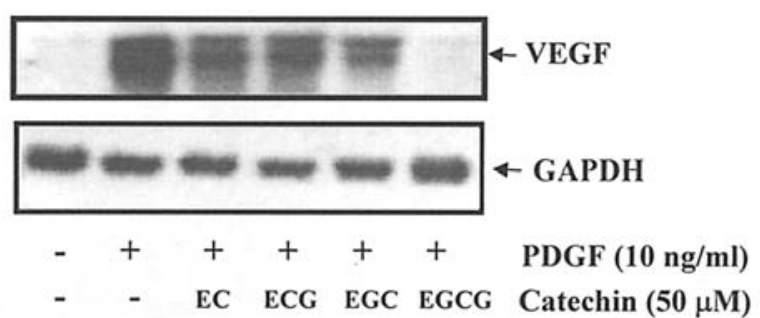

Figure 1. Effects of tea catechins on the PDGF-induced VEGF expression in hVSMCs. hVSMCs pretreated with $50 \mu \mathrm{M}$ EC, ECG, EGC and EGCG for $1 \mathrm{~h}$ were incubated with $10 \mathrm{ng} / \mathrm{ml}$ PDGF for $4 \mathrm{~h}$ and Northern blot analysis was performed for the VEGF and GAPDH mRNA expression.

A.

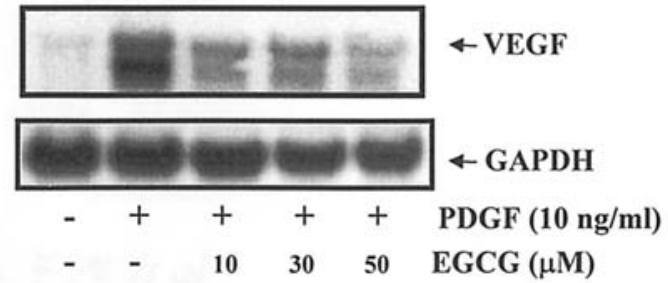

B.

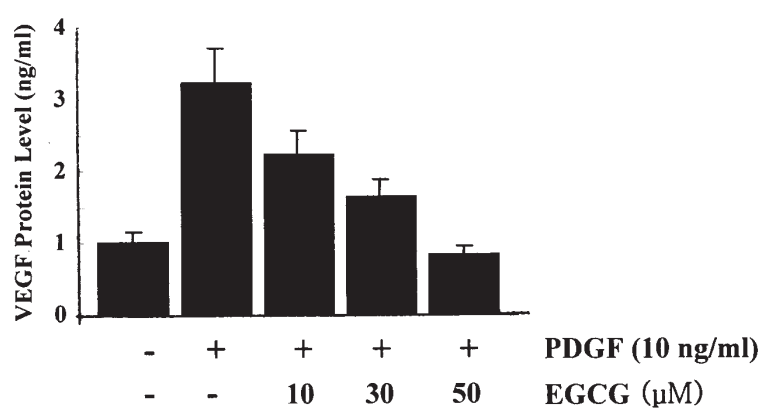

Figure 2. Inhibitory effect EGCG on the PDGF-induced VEGF mRNA and protein expression in hVSMCs. hVSMCs pretreated with 0-50 $\mu \mathrm{M}$ EGCG for $1 \mathrm{~h}$ were incubated with $10 \mathrm{ng} / \mathrm{ml}$ PDGF for $4 \mathrm{~h}$ and Northern blot analysis was performed for the VEGF mRNA expression (A). The cells pretreated with 0-50 $\mu \mathrm{M}$ EGCG for $1 \mathrm{~h}$ were incubated with $10 \mathrm{ng} / \mathrm{ml}$ PDGF for $48 \mathrm{~h}$ and culture medium was collected. ELISA was performed to determine the VEGF protein level in the culture medium. Data represent the means $\pm \mathrm{SD}$ from triplicate measurements (B).

EDTA, $1 \mathrm{mM}$ dithiothreitol, and $1 \mathrm{mM}$ phenylmethylsulfonyl fluoride]. This suspension was agitated for $30 \mathrm{~min}$ at $4^{\circ} \mathrm{C}$ and then microcentrifuged for $15 \mathrm{~min}$ at $4^{\circ} \mathrm{C}$. The resulting supernatant was stored in aliquots at $-80^{\circ} \mathrm{C}$. Protein was quantitated spectrophotometrically using the BCA assay (Pierce, Rockford, IL) with bovine serum albumin as a standard.

Electrophoretic mobility shift assay (EMSA). EMSA was performed with the Gel Shift Assay System (Promega). Briefly, oligonucleotides containing the consensus sequence for AP-1 (5'-CGC TTG ATG AGT CAG CCG GAA-3') were end-labeled with $\left[\alpha-{ }^{32} \mathrm{P}\right]$ adenosine triphosphate $(3000 \mathrm{mCi} /$ mmol; Amersham Pharmacia Biotech, Buckinghamshire, UK) using T4 polynucleotide kinase, purified in a Microspin G-25 column (Sigma) and used as a probe for EMSA. Nuclear extract proteins $(6 \mu \mathrm{g})$ were pre-incubated with the binding buffer [10 mM Tris- $\mathrm{HCl}(\mathrm{pH} 7.5), 50 \mathrm{mM} \mathrm{NaCl}, 0.5 \mathrm{mM}$ EDTA, $1 \mathrm{mM} \mathrm{MgCl}$, $0.5 \mathrm{mM}$ dithiothreitol, $4 \%$ (v/v) glycerol, and $0.05 \mathrm{mg} / \mathrm{ml}$ poly(deoxyinosine-deoxycytosine)] for $5 \mathrm{~min}$ and then incubated with the labeled probe for $15 \mathrm{~min}$ at $37^{\circ} \mathrm{C}$. Each sample was electrophoresed in a $5 \%$ non-denaturing polyacrylamide gel in $0.5 \mathrm{X}$ Tris borate-EDTA buffer at $150 \mathrm{~V}$ for $4 \mathrm{~h}$. The gel was dried and subjected to autoradiography.

Effect of EGCG pretreatment on proliferation of HUVECs stimulated by conditioned medium (CM) derived from PDGFtreated hVSMCs. CM derived from hVSMCs was prepared as follows. Cells were grown to $95-100 \%$ confluence and incubated for $48 \mathrm{~h}$ in DMEM with $1 \% \mathrm{FBS}$ and $10 \mathrm{ng} / \mathrm{ml}$ PDGF. After incubation, the supernatant (conditioned medium, $\mathrm{CM}$ ) was centrifuged, filtered, and stored at $-20^{\circ} \mathrm{C}$. To determine the effect of $\mathrm{CM}$ on endothelial cell proliferation, HUVECs $\left(5 \times 10^{3}\right)$ were seeded on 96-well plates (Falcon Laboratories, McLean, VA) and incubated for $24 \mathrm{~h}$ in DMEM containing $15 \% \mathrm{FBS}$ and $10 \mathrm{ng} / \mathrm{ml} \mathrm{bFGF}$. The medium was replaced with $\mathrm{CM}$, and the cells were incubated for $24 \mathrm{~h}$. To examine the effect of EGCG pretreatment on CM (derived from PDGF-treated hVSMCs)-induced HUVEC proliferation, hVSMCs were pretreated with 0-50 $\mu \mathrm{M}$ EGCG for $1 \mathrm{~h}$ prior to exposure to PDGF. The cell proliferation was determined by the MTT assay.

\section{Results}

Effect of EGCG on the PDGF-induced VEGF expression in hVSMCs. To examine whether tea catechins could inhibit the PDGF-induced VEGF expression in hVSMCs, cells were pretreated with 0-50 $\mu \mathrm{M}$ EGCG and other catechins for $1 \mathrm{~h}$ prior to 8 -h incubation with $10 \mathrm{ng} / \mathrm{ml} \mathrm{PDGF}$, and VEGF mRNA and protein were measured by Northern blotting and ELISA, respectively. EGCG at $50 \mu \mathrm{M}$ inhibited remarkably the PDGF-induced VEGF mRNA expression. However, other tea catechins such as EC, ECG and EGC inhibited only slightly the PDGF-induced VEGF mRNA expression at the same concentration (Fig. 1). EGCG inhibited the PDGF-induced VEGF mRNA and protein expression in a dose-dependent manner (Fig. 2). EGCG at the concentrations used did not affect the cell viability (data not shown).

Effect of EGCG on the PDGF-induced VEGF promoter activity. Next, we sought to examine the effect of EGCG on the transcriptional regulation of the VEGF gene induced by PDGF. To this end, hVSMCs were transiently transfected with the promoter-reporter construct (pGL3-VEGF) of the human VEGF gene fused to the luciferase gene. hVSMCs transfected with pGL3-VEGF showed an 8-fold increase in promoter activity after PDGF treatment (Fig. 3). When the transfected cells were pretreated with 0-50 $\mu \mathrm{M}$ EGCG before PDGF treatment, the induction of VEGF promoter activity by PDGF was inhibited dose-dependently (Fig. 3).

Effects of EGCG on signaling pathways involved in PDGFinduced VEGF expression. Our previous studies have suggested that Erk-1/2 and AP-1 signaling pathways are involved in the PDGF-induced VEGF expression in hVSMCs (14). Therefore, to study the underlying mechanisms responsible for the 


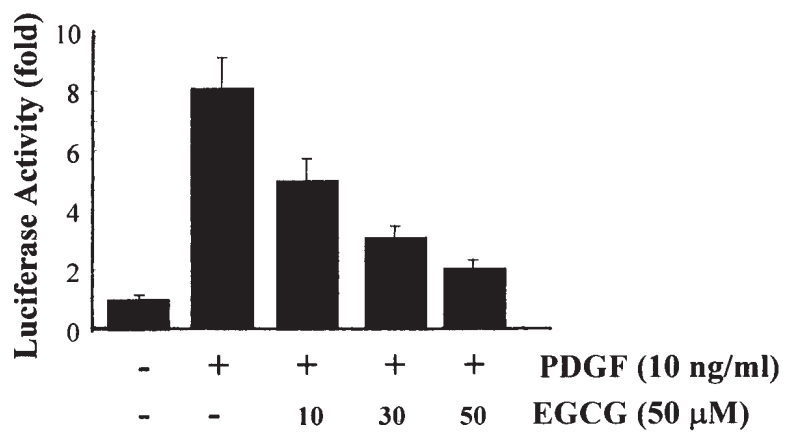

Figure 3. EGCG blocks the PDGF-induced VEGF promoter activity in hVSMCs. hVSMCs were transiently transfected with $1 \mu \mathrm{g}$ pGL3-VEGF. The transfected cells, after being pretreated with 0-50 $\mu \mathrm{M}$ EGCG for $1 \mathrm{~h}$, were incubated with $10 \mathrm{ng} / \mathrm{ml}$ PDGF for $8 \mathrm{~h}$. The cells were lysed and the luciferase activity was measured using a luminometer. Data represent the means \pm SD from triplicate measurements.

A.

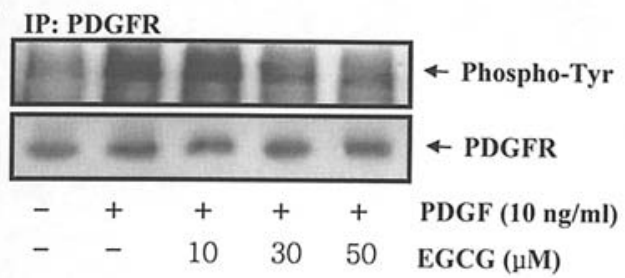

B.

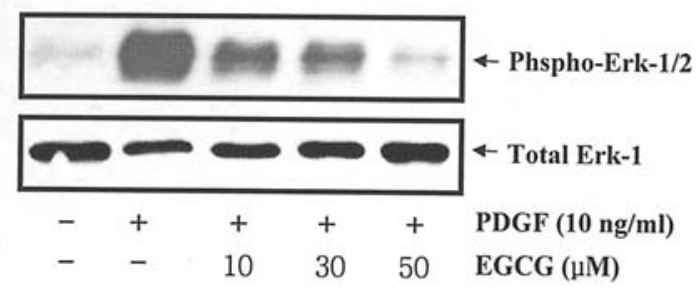

C.

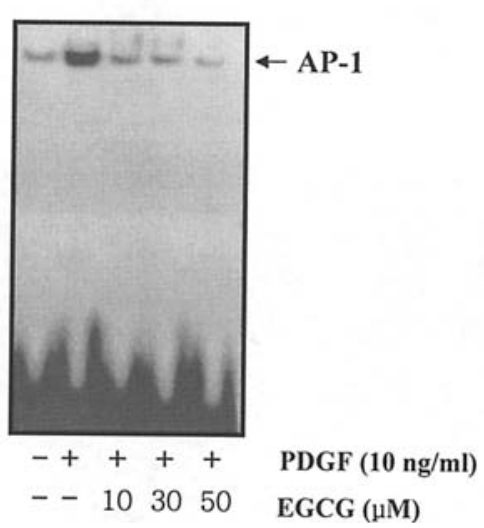

Figure 4. EGCG blocks the PDGF-induced activation of PDGF receptor, Erk-1/2 and AP-1. hVSMCs pretreated with 0-50 $\mu \mathrm{M}$ EGCG for $1 \mathrm{~h}$ were incubated with $10 \mathrm{ng} / \mathrm{ml}$ PDGF for $15 \mathrm{~min}$. PDGF receptor was immunoprecipitated (IP) from the cell lysates and then analyzed for phosphorylated and total PDGF receptor by Western blot analysis (A). The cell lysates were determined for the phosphorylated and total ERk-1/2 by Western blot analysis (B). The cells pretreated with $0-50 \mu \mathrm{M}$ EGCG for $1 \mathrm{~h}$ were incubated with $10 \mathrm{ng} / \mathrm{ml}$ PDGF for $8 \mathrm{~h}$ and nuclear proteins were extracted. EMSA was performed to determine the activated AP-1 using a radiolabeled oligonucleotide probe $(\mathrm{C})$.

inhibitory effect of EGCG on PDGF-induced VEGF expression, the effects of EGCG on PDGF-induced activation of

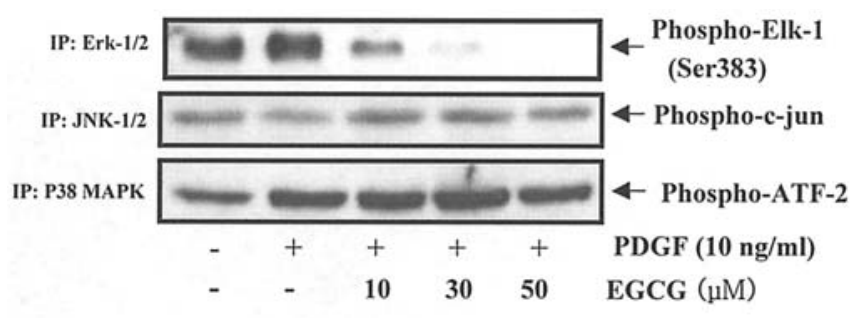

Figure 5. Inhibition by EGCG of the Erk-1/2 activity. The cell lysates from the hVSMCs treated with $10 \mathrm{ng} / \mathrm{ml}$ PDGF for $30 \mathrm{~min}$ were prepared. The indicated kinases were immunoprecipitated (IP) from the lysates and incubated with the appropriated protein substrates and ATP in the presence of $0-50 \mu \mathrm{M}$ EGCG for $30 \mathrm{~min}$. After incubation, the reaction mixtures were electrophoresed and the incorporation of phosphate into the protein substrates was detected using the appropriate phosphate-specific antibodies. The immunoblots depicted correspond to Erk-1/2 (phospho-Elk-1), JNK-1/2 (phospho-c-jun) and P38 MAPK (phospho-ATF-2).

the PDGF receptor, Erk-1/2 and AP-1 were examined. The results showed that EGCG inhibited the PDGF-induced phosphorylation of the PDGF receptor in a dose-dependent manner without affecting the protein level of the PDGF receptor (Fig. 4A). EGCG inhibited the PDGF-induced phosphorylation of Erk-1/2 in a dose-dependent manner, too. The level of total Erk-1/2 was not significantly altered by EGCG treatment (Fig. 4B). In addition, EGCG inhibited remarkably the PDGF-induced activation of AP-1, as revealed by EMSA (Fig. 4C). Thus, EGCG was shown to inhibit not only the PDGF-induced tyrosine phosphorylation of the PDGF receptor but also the downstream activation of Erk-1/2 and AP-1.

Effect of EGCG on Erk-1/2 activity. Since EGCG has been reported to be a potent inhibitor of some enzymes (17), we next examined whether activated Erk-1/2 could be directly affected by EGCG. Extracts were prepared from PDGFstimulated and -non-stimulated cells, and Erk-1/2 and other MAP kinases were collected by immunoprecipitation. The precipitated kinases were then incubated in in vitro kinase reactions in the presence of $0-50 \mu \mathrm{M}$ EGCG. As shown in Fig. 5, EGCG inhibited potently both the PDGF-induced and constitutive Erk-1/2 activity. In contrast, however, JNK-1/2 and P38 MAPK activity was not significantly affected by EGCG. The above results suggest that EGCG could inhibit not only the PDGF-induced activation of Erk-1/2 but also the activity of activated Erk-1/2.

Effect of EGCG pretreatment on proliferation of HUVECS stimulated by conditioned medium (CM) derived from PDGFtreated hVSMCs. Our results showed that EGCG could remarkably inhibit the PDGF-induced VEGF expression in hVSMCs. Also, our previous studies showed that conditioned medium (CM) obtained from PDGF-treated hVSMCs could stimulate the growth of HUVECs and this stimulatory effect was significantly abolished by anti-VEGF antibody, suggesting that VEGF derived from PDGF-treated hVSMCs may stimulate the EC proliferation. Therefore, the effect of EGCG pretreatment on the proliferation of HUVECs stimulated by CM derived from PDGF-treated hVSMCs was examined. As shown in Fig. 6, the CM derived from PDGF-treated hVSMCs remarkably stimulated the in vitro growth of HUVECs, and 


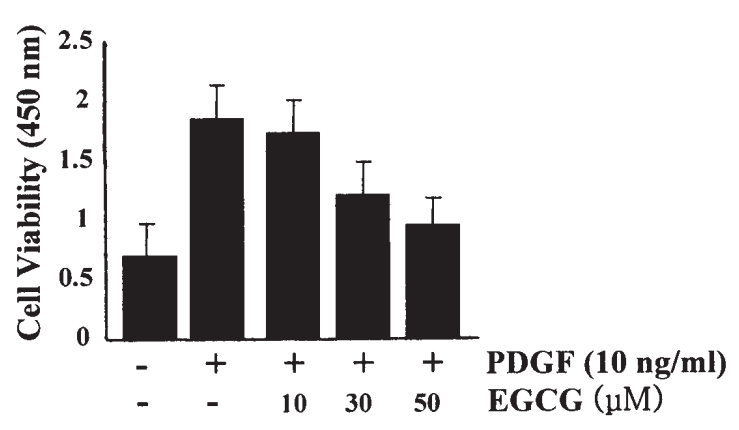

Figure 6. EGCG pretreatment inhibits the proliferation of HUVECs stimulated by conditioned medium (CM) derived from PDGF-treated hVSMCs. hVSMCs, after being pretreated with $0-50 \mu \mathrm{M}$ EGCG for $1 \mathrm{~h}$, were incubated with $10 \mathrm{ng}$ / $\mathrm{ml}$ PDGF for $48 \mathrm{~h}$ and the medium (CM) was collected. HUVECs were incubated with $\mathrm{CM}$ for $24 \mathrm{~h}$ and the number of cells was counted using MTT. Data represent the means \pm SD from triplicate measurements.

when the CM was collected from the cells pretreated with EGCG, its proliferation-stimulatory effect was significantly abolished.

\section{Discussion}

The interest in green tea as a cancer chemopreventive agent in humans has increased for several reasons: a) in epidemiological studies, green tea lowers the risk of various cancers among people who consume a large amount of green tea (18); b) green tea protects against the development and progression of skin, lung, mammary gland, and gastrointestinal tract cancers in animal models (4); c) green tea extracts stimulate apoptosis of various cancer cell lines, such as prostate, lymphoma, colon, and lung in vitro (19); and d) green tea consumption is associated with few adverse events and can be obtained easily at a low cost (20).

The anti-carcinogenic effects of green tea have been attributed to the biological activity of its polyphenol components. EGCG is the most abundant of the green tea polyphenols, accounting for $>40 \%$ (5). Several molecular mechanisms have been suggested for EGCG's observed anticancer effect, including suppression of ligand binding to the EGF receptor (21), inhibition of protein kinase C (22), lipoxygenase and cyclooxygenase activity (5), and induction of apoptotic cell death and arrest of the cell cycle in tumor cells (20).

In this study, we demonstrated that EGCG inhibits VEGF induction by PDGF in hVSMCs at a transcriptional level. Recently, it was proposed that EGCG may exert at least part of its anti-cancer effect by inhibiting angiogenesis through blocking the induction of vascular endothelial growth factor (VEGF). Our results also showed that EGCG inhibited HUVEC proliferation stimulated by CM derived from PDGFtreated hVSMCs (14), supporting our earlier contention that VEGF is an in vivo survival factor for tumor endothelium (23). In another tumor system, Bertolini et al (24) demonstrated that treatment with green tea led to an inhibition of angiogenesis and induction of endothelial and tumor cell apoptosis in an animal model of human high-grade non-Hodgkin's lymphoma. These findings suggest that down-regulation of VEGF by EGCG may not only inhibit the new blood vessel formation and cell proliferation within tumors, but also lead to tumor cell apoptosis.

PDGF is a potent mitogen and survival factor for VSMC and tyrosine phosphorylation in the PDGF receptor serves as a critical line between extracellular PDGF stimulation and intracellular signaling. In this study, we demonstrated that EGCG inhibited the phosphorylation of tyrosines in the PDGF receptor elicited by PDGF without affecting the protein expression of PDGF receptors in hVSMCs. Several possible mechanisms by which EGCG inhibits the phosphorylation of the PDGF receptor are suggested. Liang et al (21) reported that EGCG inhibited receptor type protein (epidermal growth factor receptor, fibroblast growth factor receptor and PDGF receptor) tyrosine kinase whereas it scarcely inhibited serineand threonine-specific protein kinases such as protein kinase A and C. EGCG, like tyrphostin AG1296, may induce conformational changes at the ATP-binding site of the PDGF receptor, thereby inhibiting its tyrosine phosphorylation $(25,26)$. On the other hand, Sakata et al (27) suggested that the inhibition of PDGF-induced receptor phosphorylation and its downstream activation by EGCG may be attributed to the inhibition of PDGF and its receptor binding. EGCG also can form complexes with biologic macromolecules such as lipids, carbohydrates, protein, and nucleic acids (19). Weber et al (28) showed that EGCG was incorporated into different cellular components including cell surface membranes, which lead to a trapping of PDGF to non-receptor binding sites and reduced PDGF binding to its receptors.

Previously, we reported that ERK-1/2 and AP-1 signaling pathways were involved in PDGF-induced VEGF expression in hVSMCs and suggested that these paracrine signaling pathways induce endothelial cell proliferation (14). In this study, EGCG was shown to inhibit the activation of Erk-1/2 and transcription factor AP-1 in PDGF-treated hVSMCs. Since EGCG inhibited the phosphorylation of PDGF receptor, it would be logical to assume that the reduction in activity of kinases downstream of the PDGF receptor was due to the reduction in PDGF receptor activity. In addition, it was shown that EGCG could directly inhibit the Erk-1/2 activity in a cell free system, although the mechanism by which EGCG inhibited the Erk-1/2 activity remained unknown. Thus, activation of Erk-1/2 might be inhibited by a dual effect of EGCG in the cells: the suppression of upstream PDGF receptor phosphorylation and the direct inhibition of Erk-1/2 activity.

Our results suggest that EGCG may exert anti-angiogenic and anti-proliferative effects by inhibiting PDGF-induced VEGF expression at multiple signal levels, supporting the role of green tea as a cancer chemopreventive agent. Further studies are needed to elucidate the detailed mechanisms by which EGCG inhibits the VEGF expression and to examine whether EGCG exerts the same effects in vivo.

\section{Acknowledgements}

This work was supported by Korea Research Foundation (BK 21 Program) for graduate studentships to M.H. Kim and by the Korea Science and Engineering Foundation through the Medical Research Center (R13-2002-013-00000-0) at Chonnam National University. 


\section{References}

1. Yu GP, Hsieh CC, Wang LY, Yu SZ, Li XL and Jin TH: Greentea consumption and risk of stomach cancer: a population-based case-control study in Shanghai, China. Cancer Causes Control 6: 532-538, 1995.

2. Ji BT, Chow WH, Hsing AW, McLaughlin JK, Dai Q, Gao YT, Blot WJ and Fraumeni JF Jr: Green tea consumption and the risk of pancreatic and colorectal cancers. Int J Cancer 70: 255-258, 1997.

3. Jung YD, Kim MS, Shin BA, Chay KO, Ahn BW, Liu W, Bucana CD, Gallick GE and Ellis LM: EGCG, a major component of green tea, inhibits tumour growth by inhibiting VEGF induction in human colon carcinoma cells. Br J Cancer 84: 844-850, 2001.

4. Rogers AE, Hafer LJ, Iskander YS and Yang S: Black tea and mammary gland carcinogenesis by 7,12-dimethylbenz[a]anthracene in rats fed control or high fat diets. Carcinogenesis 19: 1269-1273, 1998.

5. Stoner GD and Mukhtar H: Polyphenols as cancer chemopreventive agents. J Cell Biochem Suppl 22: 169-180, 1995.

6. Jung YD and Ellis LM: Inhibition of tumour invasion and angiogenesis by epigallocatechin gallate (EGCG), a major component of green tea. Int J Exp Pathol 82: 309-416, 2001.

7. Antoine M, Wirz W, Tag CG, Mavituna M, Emans N, Korff T, Stoldt V, Gressner AM and Kiefer P: Expression pattern of fibroblast growth factors (FGFs), their receptors and antagonists in primary endothelial cells and vascular smooth muscle cells. Growth Factors 23: 87-95, 2005.

8. Hicklin DJ and Ellis LM: Role of the vascular endothelial growth factor pathway in tumor growth and angiogenesis. J Clin Oncol 23: 1011-1027, 2005.

9. Ferrara N: Molecular and biological properties of vascular endothelial growth factor. J Mol Med 77: 527-543, 1999.

10. Reinmuth N, Liu W, Jung YD, Ahmad SA, Shaheen RM, Fan F, Bucana CD, McMahon G, Gallick GE and Ellis LM: Induction of VEGF in perivascular cells defines a potential paracrine mechanism for endothelial cell survival. FASEB J 15: 1239-1241, 2001.

11. Jung YD, Liu W, Reinmuth N, Ahmad SA, Fan F, Gallick GE and Ellis LM: Vascular endothelial growth factor is up-regulated by interleukin-1 beta in human vascular smooth muscle cells via the P38 mitogen-activated protein kinase pathway. Angiogenesis 4: 155-162, 2001.

12. Pertovaara L, Kaipainen A, Mustonen T, Orpana A, Ferrara N, Saksela O and Alitalo K: Vascular endothelial growth factor is induced in response to transforming growth factor-beta in fibroblastic and epithelial cells. J Biol Chem 269: 6271-6274, 1994.

13. McLaren J, Prentice A, Charnock-Jones DS, Millican SA, Muller KH, Sharkey AM and Smith SK: Vascular endothelial growth factor is produced by peritoneal fluid macrophages in endometriosis and is regulated by ovarian steroids. J Clin Invest 98: 482-489, 1996.

14. Chang HJ, Park JS, Kim MH, Hong MH, Kim KM, Kim SM, Shin BA, Ahn BW and Jung YD: Extracellular signal-regulated kinases and AP-1 mediate the up-regulation of vascular endothelial growth factor by PDGF in human vascular smooth muscle cells. Int J Oncol 28: 135-141, 2006.
15. Berse B, Brown LF, van de Water L, Dvorak HF and Senger DR: Vascular permeability factor (vascular endothelial growth factor) gene is expressed differentially in normal tissues, macrophages, and tumors. Mol Biol Cell 3: 211-220, 1992.

16. Akagi Y, Liu W, Zebrowski B, Xie K and Ellis LM: Regulation of vascular endothelial growth factor expression in human colon cancer by insulin-like growth factor-I. Cancer Res 58: 4008-4014, 1998.

17. Sah JF, Balasubramanian S, Eckert RL and Rorke EA: Epigallocatechin-3-gallate inhibits epidermal growth factor receptor signaling pathway. Evidence for direct inhibition of ERK1/2 and AKT kinases. J Biol Chem 279: 12755-12762, 2004.

18. Kono S, Ikeda M, Tokudome S and Kuratsune M: A casecontrol study of gastric cancer and diet in northern Kyushu, Japan. Jpn J Cancer Res 79: 1067-1074, 1988.

19. Yang CS and Wang ZY: Tea and cancer. J Natl Cancer Inst 85 : 1038-1049, 1993.

20. Fujiki H, Suganuma M, Okabe S, Sueoka N, Komori A, Sueoka E, Kozu T, Tada Y, Suga K, Imai K and Nakachi K: Cancer inhibition by green tea. Mutat Res 402: 307-310, 1998.

21. Liang YC, Lin-Shiau SY, Chen CF and Lin JK: Suppression of extracellular signals and cell proliferation through EGF receptor binding by (-)-epigallocatechin gallate in human A431 epidermoid carcinoma cells. J Cell Biochem 67: 55-65, 1997.

22. Kitano K, Nam KY, Kimura S, Fujiki H and Imanishi Y: Sealing effects of (-)-epigallocatechin gallate on protein kinase $\mathrm{C}$ and protein phosphatase 2A. Biophys Chem 65: 157-164, 1997.

23. Shaheen RM, Davis DW, Liu W, Zebrowski BK, Wilson MR, Bucana CD, McConkey DJ, McMahon G and Ellis LM: Antiangiogenic therapy targeting the tyrosine kinase receptor for vascular endothelial growth factor receptor inhibits the growth of colon cancer liver metastasis and induces tumor and endothelial cell apoptosis. Cancer Res 59: 5412-5416, 1999.

24. Bertolini F, Fusetti L, Rabascio C, Cinieri S, Martinelli G and Pruneri G: Inhibition of angiogenesis and induction of endothelial and tumor cell apoptosis by green tea in animal models of human high-grade non-Hodgkin's lymphoma. Leukemia 14: 1477-1482, 2000.

25. Kovalenko M, Ronnstrand L, Heldin CH, Loubtchenkov M, Gazit A, Levitzki A and Bohmer FD: Phosphorylation sitespecific inhibition of platelet-derived growth factor beta-receptor autophosphorylation by the receptor blocking tyrphostin AG1296. Biochemistry 36: 6260-6269, 1997.

26. Masuda M, Suzui M, Lim JT and Weinstein IB: Epigallocatechin-3-gallate inhibits activation of HER-2/neu and downstream signaling pathways in human head and neck and breast carcinoma cells. Clin Cancer Res 9: 3486-3491, 2003.

27. Sakata R, Ueno T, Nakamura T, Sakamoto M, Torimura T and Sata M: Green tea polyphenol epigallocatechin-3-gallate inhibits platelet-derived growth factor-induced proliferation of human hepatic stellate cell line LI90. J Hepatol 40: 52-59, 2004.

28. Weber AA, Neuhaus T, Skach RA, Hescheler J, Ahn HY, Schror K, Ko Y and Sachinidis A: Mechanisms of the inhibitory effects of epigallocatechin-3-gallate on platelet-derived growth factor-BB-induced cell signaling and mitogenesis. FASEB J 18: 128-130, 2004. 